\title{
A compreensão das relações entre escola e seu entorno na formação de professores de Biologia: uma abordagem crítica da educação ambiental no estágio supervisionado.
}

Understanding the relationship between school and its environment in teacher training in Biology: a critical approach to environmental education in the supervised stage.

La comprensión de las relaciones entre escuela y su entorno en la formación de profesores de Biología: un enfoque crítico de la educación ambiental en la etapa supervisada.

Pollyana Cristina Alves Cardoso Mestranda no Programa de Pós-graduação em Educação Científica e Ambiental, UFLA, Brasil Pollyana.cardoso@estudante.ufla.br

Luiz Otávio Cortez Mestrando no Programa de Pós-graduação em Ecologia Aplicada Locortez.bio@gmail.com

Lorena Felix Marocci Bouças Mestranda no Programa de Pós-graduação em Ecologia Aplicada lorenamarocci@hotmail.com

Marina Battistetti Festozo Professora Dra. no Programa de Pós-graduação em Educação Científica e Ambiental Marina.festozo@ufla.br 


\section{RESUMO}

O objetivo deste trabalho é compreender e analisar as relações que a escola estabelece com o seu meio, incluindo sua comunidade, para conhece a história desses ambientes de maneira crítica, compreendendo seus aspectos econômicos, políticos, sociais e ambientais, pois entendemos essa análise como um estudo da educação ambiental crítica. Os pesquisadores eram os estagiários - futuros professores de Biologia - que participaram ativamente da organização e realização de todo processos de pesquisa. Foram realizadas entrevistas com professores de duas escolas públicas, uma periférica e outra central, e com as pessoas das comunidades do entorno dessas escolas. Os resultados mostraram que, apesar de ser uma orientação dos documentos de referência para educação nacional, as escolas em questão têm dificuldade em estabelecer uma relação contínua e participativa com as comunidades do seu entorno. Contudo, as entrevistas mostraram que os professores têm interesse em utilizar o bairro durante o processo de ensino-aprendizagem, assim como os moradores do entorno enxergam que essa relação pode render bons frutos. Conhecer a escola, a comunidade e as relações que as mesmas estabelecem e podem vir a estabelecer, é uma forma de compreender o ambiente e contribuir para a formação de professores críticos e reflexivos. Desta forma, ao oferecer os resultados de uma pesquisa como essa para as escolas, as mesmas poderão refletir sobre uma possível aproximação pedagógica com a comunidade. Assim como, os professores tendo a possibilidade de utilizar o bairro como espaço de aprendizagem, os alunos poderão compreender melhor como os conteúdos se relacionam com o seu cotidiano.

PALAVRAS-CHAVE: Educação ambiental crítica. Pesquisa do entorno. História.

\section{ABSTRACT}

The goal of this work is to understand an analyse the relations school lays down with its environment, including its community, to know this environment history in a critical way, comprising its economical, political, social an environmental aspects, because we understand this analysis as a critical environmental education study. The researchers were interns - future biology teachers - that actively participated in the organization and realization of all research processes. Interviews was conducted with teachers of two public schools, a peripheral and a central one, and with the people in the community around these schools. The results showed that, despite being an orientation of the reference documents for national education, the schools in question have difficulty in establishing a continuous and participative relationship with the communities around them. Nevertheless, the interviews showed that the teachers are interest in use the neighborhood during the teaching-learning process, as well as the residents of the surrounding area see that this relationship may yield good results. To know the school, the community and the current and potential relationship stablished between the both is one way to understand the environment and to contribute for a critical and reflexive teachers formation. In this way, when offering the results of a research like this for the schools, they can reflect on a possible pedagogical approach with the community. As well as, teachers having the possibility of using the neighborhood as a learning space, students will be able to better understand how the contents relate to their daily life.

KEY-WORDS: Critical environmental education. Environmental research. History.

\section{RESUMEN}

El objetivo de este trabajo es comprender y analizar las relaciones que la escuela establece con su medio, incluyendo su comunidad, para conocer la historia de esos ambientes de manera crítica, comprendiendo sus aspectos económicos, políticos, sociales y ambientales, pues entendemos ese análisis como un "estudio de la educación ambiental crítica. Los investigadores eran los pasantes - futuros profesores de Biología - que participaron activamente en la organización y realización de todo proceso de investigación. Se realizaron entrevistas con profesores de dos escuelas públicas, una periférica y otra central, y con las personas de las comunidades del entorno de esas escuelas. Los resultados mostraron que, a pesar de ser una orientación de los documentos de referencia para la educación nacional, las escuelas en cuestión tienen dificultades para establecer una relación continua y participativa con las comunidades de su entorno. Sin embargo, las entrevistas mostraron que los profesores tienen interés en utilizar el barrio durante el proceso de enseñanza-aprendizaje, así como los habitantes del entorno perciben que esa relación puede dar buenos frutos. Conocer la escuela, la comunidad y las relaciones que las mismas establecen y pueden venir a establecer, es una forma de comprender el ambiente y contribuir a la formación de profesores críticos y reflexivos. De esta forma, al ofrecer los resultados de una investigación como esa para las escuelas, las mismas podrán reflexionar sobre una posible aproximación pedagógica con la comunidad. Así como, los profesores teniendo la posibilidad de utilizar el barrio como espacio de aprendizaje, los alumnos podrán comprender mejor cómo los contenidos se relacionan con su cotidiano.

PALBRAS-CHAVE: Educación ambiental crítica. Investigación del entorno. Historia. 


\section{INTRODUÇÃO}

A educação é um processo de humanização que o ser humano precisa para poder se libertar dos mecanismos ideológicos de reprodução social, que impõe um modelo societário hegemônico e impede o pensamento crítico e reflexivo (LAYRARGUES, 2012).

Nesse modelo de sociedade prevalece a alienação, pois os indivíduos não pensam sobre si, sobre o mundo em que vivem e sobre o trabalho que exercem na sociedade (LAYRARGUES, 2012). Para escapar desta condição eles precisam conhecer o ambiente em que vivem, com todas as suas particularidades históricas, sociais, ambientais e culturais, além de conhecer, compreender e refletir sobre os mecanismos de dominação e exploração dos humanos e da natureza (LAYRARGUES, 2012).

Reconhecendo as amarras que impedem a cidadania e a autonomia de exercer um trabalho consciente, é possível se pensar na transformação desse modelo de sociedade. Partindo, além de tudo, de uma educação crítica, reflexiva e transformadora, que acontece por meio da ação política, da luta social e da participação democrática na esfera pública (LAYRARGUES, 2012).

Uma das áreas do conhecimento que se volta para o ensino e reflexão de tais valores e para a compreensão crítica da realidade é a Educação Ambiental, por meio dela os alunos se apropriam de algumas ferramentas necessárias para participar ativamente na sociedade, o conhecimento crítico do ambiente. A participação na sociedade envolve o conhecimento sobre a mesma para que o indivíduo possa refletir sobre a história e sobre os caminhos atuais que a sociedade vem tomando (FESTOZO, et. al., 2018).

Contudo, os interesses da classe burguesa, muitas das vezes, estão acima das necessidades das demais pessoas da sociedade, e por conta disso, é oferecido um ensino de ótima qualidade para poucos relegando um ensino de qualidade técnica para as pessoas da classe trabalhadora, as quais não tem, desta forma, seus direitos garantidos.

Nesse sentido, há uma desvalorização do sistema básico de ensino público, pois fica muito claro como a ideologia dominante da burguesia está impregnada no sistema educacional. Ou seja, aos trabalhadores e estudantes da escola pública, o conhecimento elaborado não é disponibilizado. Ao invés disso, Ihes é concedido o mínimo com relação à sua função produtiva (SAVIANI, 1992).

Muitas pessoas trabalham arduamente para ter direito apenas ao básico para sua sobrevivência, que é algo comum até mesmo para as outras espécies animais, como alimento e moradia. Diante disso, Saviani (1992) reflete que essas pessoas não conseguem ter acesso às outras produções humanas como arte, ciência e literatura, e essa situação acaba reforçando a desigualdade social, não permitindo também que a pessoa possa refletir sobre a sua realidade. É por isso que a educação é um direito que deve ser garantido a toda a população, pois proporciona ao indivíduo o desenvolvimento de sua humanidade, ou seja, a apropriação de uma produção histórica de saberes, o que é chamado de segunda natureza pelo autor. 0 homem possui uma segunda natureza que é por onde desenvolvemos nossas habilidades, que muitas vezes são tratadas como naturais, no entanto, essas habilidades só são adquiridas a partir de um processo sistemático de educação, que assim como a arte e a cultura são produtos do trabalho (SAVIANI, 1992). 
Nessa perspectiva, quando este conhecimento não é oferecido a todas as pessoas da sociedade, os trabalhadores são incapazes de pensar sobre sua vida e sobre o ambiente em que vivem, pois estão desprovidos das devidas ferramentas que lhes possibilitem uma posição crítico-reflexiva. Da mesma maneira não conseguem se apropriar do produto do seu trabalho, pois estão sujeitos a uma lógica de produção em massa (SAVIANI, 1992).

Dessa forma, fica evidente a dificuldade que a população menos favorecida tem de participar dos assuntos públicos. Segundo Festozo et. al. (2018) esta participação é, portanto, construída historicamente, porque ao mesmo tempo em que há essa falta de reflexão e participação, nos momentos de luta e resistência lhes é concedido alguns direitos sociais, e assim, pequenas transformações vão sendo possibilitadas.

Nesse sentido, segundo Saviani (1992) o maior potencial de transformação está na escola. Essa formação crítica, reflexiva e cidadã proporcionada pela escola é, como afirma Festozo et. al. (2018), baseada em escolhas e projetos de sociedade, e por isso é política.

Nesse caminho, a possibilidade de problematizar estas questões, está na Educação Ambiental Crítica, tendência da EA que se preocupa em situar o ser humano no ambiente e compreender suas relações com o mesmo, possibilitando uma visão ampla e integral do ambiente, pois leva em consideração a conservação do meio ambiente, o ser humano e suas relações para transformação da sociedade.

Contudo, por muito tempo a Educação Ambiental tem sido relegada apenas à conservação dos recursos naturais e da fauna. Os indivíduos têm o costume de pensar que a temática só diz respeito ao ambiente arborístico, todavia é preciso salientar que a EA possui algumas macrotendências que se despontaram historicamente (LAYRARGUES, 2012).

Uma dessas macrotendências que ainda predomina nos dias atuais no sistema escolar é a tendência conservacionista. Essa tendência está preocupada com a conservação da fauna e da flora, cultivando nos indivíduos um cuidado com o meio ambiente para que suas espécies animais e vegetais não entrem em extinção. Contudo, a tendência conservacionista é um pouco problemática e limitada, pois há o predomínio, principalmente, de ações individuais e comportamentos no âmbito privado e doméstico (LAYRARGUES, 2012).

Outra macrotendência que desponta na década de 80 é a pragmática, que vem com a preocupação do desenvolvimento sustentável e o consumo sustentável. Essa tendência surge por conta hegemonia neoliberal instaurada nessa época. Segundo Layrargues (2012), a mesma teria todas as potencialidades para fazer uma leitura crítica da realidade, fazendo uma reflexão do impacto do lixo advindo do atual modelo desenvolvimentista, contudo, só serviu como um mecanismo de compensação para corrigir as imperfeições do sistema produtivo.

Nesse sentido, ambas não se preocupam com as questões sociais e políticas da sociedade, sujeitam os seres humanos à condição de causadores e vítimas da crise ambiental, desconsiderando qualquer recorte social (LAYRARGUES, 2012).

Por conta desses problemas, a educação ambiental crítica e transformadora é uma tendência que permite relacionar as questões sociais, políticas e culturais com o meio ambiente. Desta maneira, os indivíduos são capazes de refletir sobre todas estas questões que estão colocadas no ambiente, pois além de discutir questões relacionadas à gestão ambiental, também faz uma leitura crítica da dominação do ser humano e da acumulação de capital. Desta forma, esta 
tendência busca uma transformação social, para superação das desigualdades sociais e injustiças socioambientais (LAYRARGUES, 2012).

A educação ambiental crítica se propõe então a contextualizar e politizar o debate ambiental, articulando as dimensões da sustentabilidade e problematizando as contradições dos modelos de desenvolvimento da sociedade (LAYRARGUES, 2012).

Por conta disso, essa educação ambiental crítica precisa estar presente na escola, para que os alunos tomem a consciência que preservar o ambiente requer antes conhecê-lo com todas as suas particularidades sociais, culturais e políticas.

É na escola que o indivíduo se apropria dos saberes básicos e essenciais para a sua integração e participação em sua profissão e na sociedade, a escola é um espaço para aquisição da ciência, do saber elaborado que deve ser permeado pela cultura de cada aluno. Este conhecimento que tem na realidade deve ser acessível a todos, pois a não apropriação do conhecimento pode ser usado para dominação do indivíduo (SAVIANI, 1992).

Diante disso, para que o clássico e universal façam parte do conhecimento de todos, é necessário tomar como ponto de partida a realidade de cada um. Para isso, é necessário também compreender a importância da Justiça social, ou seja, de se oferecer a todos o direito de educação, como forma de inclusão do conhecimento, já que este pode proporcionar ao indivíduo uma maior compreensão do meio em que vive e assim ter consciência de seus atos e de seu papel em seu meio.

Para isso, a escola precisa criar laços com a comunidade, para que a realidade dos alunos seja inserida na aula, e para que eles conheçam o lugar em que vivem e as relações ali estabelecidas. Isso pode acontecer ao se aliar os conteúdos curriculares com as questões que permeiam aquela comunidade, mas a participação da comunidade na escola também pode se dar por meio de atividades extracurriculares que tem o papel de formação cultural: arte, cultura, música, dança, entre outras, além de nos momentos de formulação e revisão do Projeto Político Pedagógico, PPP, no qual a comunidade pode participar de maneira mais ativa das decisões escolares que implicam seus filhos. Ademais, a partir de um contato mais próximo entre ambas, a escola tendo o poder de fomentar novas ideias que atendam às demandas dessa comunidade, poderá auxiliá-la em diversas questões por meio de projetos participativos. Essa aproximação pode acontecer por mediação das Universidades.

As universidades públicas são promovidas pelo governo e mantidas com dinheiro público, portanto, espera-se que todo conhecimento produzido dentro da instituição seja voltada para a melhoria da sociedade e para o povo. Ela desempenha um grande papel transformador em nossa sociedade, pois em nosso país grande parte do conhecimento científico é produzido nessas instituições, podendo contribuir tanto para formação de profissionais quanto para o bem-estar da sociedade ao promover a produção e universalização desse conhecimento. Como instituição de ensino superior, a universidade engloba um conjunto de faculdades destinadas à especialização profissional e científica, e para isto, oferece aos alunos atividades de ensino, pesquisa e extensão que, por sua vez, são os três pilares que a sustentam (SEVERINO, 2002). Porém, alguns desses pilares têm sido deixados de lado, causando um desequilíbrio na função social da Universidade, além do que poucas vezes podemos observar a real integração deste tripé. 
Uma das formas de promover o ensino, a pesquisa e a extensão de maneira mais integrada na formação de professores, é por meio do estágio supervisionado nas Instituições educativas, especialmente as públicas.

O Ensino é a transmissão ou a apropriação do conhecimento por intermédio dos professores, a Pesquisa cumpre o papel de produzir esse conhecimento, enquanto a Extensão é o diálogo da universidade com a comunidade, abrangendo toda a troca de conhecimentos e saberes. Esses três elementos quando unidos, tornam a universidade completa (SLEUTJES, 1999).

Nessa perspectiva, aproximando comunidade, escola e universidade, poderá se alcançar uma participação social dos indivíduos, ao proporcionar uma formação cidadã dos mesmos, que os preparem para refletir e agir. Nesse sentido, buscamos uma transformação destas relações, para que elas não sejam tão marcantes e deterministas, que começa pela educação. Por este motivo há a necessidade de uma educação ambiental crítica, que está relacionada com a emancipação e participação social (FESTOZO et. al., 2018).

Diante disso, abordamos neste trabalho uma forma de aproximar escola e universidade para diagnóstico das dificuldades encontradas pela escola e pelos professores de aproximar a comunidade da mesma. Entendendo a relevância desse processo para a formação de cidadãos críticos, reflexivos e participativos na sociedade, assim como para a formação de futuros professores, que precisam conhecer estas questões e criar possibilidades de enfrentamento.

\section{OBJETIVO}

Com estas preocupações, torna-se nosso objetivo entender as relações que a escola estabelece com a comunidade, de forma a compreender o ambiente escolar de forma ampla, contextualizada e crítica, em suas relações sociais, políticas, econômicas e ambientais de participação.

\section{METODOLOGIA}

A pesquisa em questão foi pensada como atividade coletiva da turma do Estágio Supervisionado III do curso de Ciências Biológicas de uma Universidade Federal, atividade ofertada no segundo período de 2017 que se relaciona com o ato de Educar pela Pesquisa (DEMO, 2011). A pesquisa realizada pelos alunos teve o intuito de trabalhar com os docentes em formação o processo de pesquisar e produzir o saber, já que essa atividade diz respeito à capacidade de produzir conhecimento adequado para compreender e interpretar determinada realidade (TOZONI-REIS, 2008), fato, fenômeno ou relação social (MEKSENAS, 2002).

A pesquisa realizada pelo grupo tratou-se de uma Pesquisa Qualitativa, que segundo Ludke \& André (1986) o ambiente natural em que o pesquisador está inserido se torna sua fonte direta de dados. Além disso, nesse tipo de pesquisa, o problema está mais relacionado com o processo, e não com o produto final.

Ainda, o tipo de pesquisa foi a pesquisa-ação-participativa, que articula a produção de conhecimentos com a ação educativa, além de investigar e produzir conhecimentos sobre a realidade a ser estudada, realizando um processo educativo para o enfrentamento dessa mesma realidade (TOZONI-REIS, 2007). A pesquisa-ação-participativa é uma experiência que se caracteriza pela participação constante do pesquisador em seu meio de trabalho. Segundo 
Tozoni-Reis (2012) nessa metodologia de pesquisa se faz uma intervenção no espaço social em que se realiza a investigação. Desta forma, a investigação de determinado processo ambiental se articula diretamente com o ato de educar, ou seja, ao mesmo tempo em que busca compreender determinada questão que está colocada no ambiente, este ato se configura como um processo educativo para quem participa dele. Assim, os participantes da pesquisa deixam de ser meros objetos de pesquisa para se tornaram sujeitos (TOZONI-REIS, 2012).

Por ser uma pesquisa-ação-participativa, o planejamento foi feito de forma coletiva, onde todos os integrantes da turma participaram das decisões tomadas, assim como da realização da pesquisa. Segundo Tozoni-Reis (2007) esse processo é conhecido como planejamento participativo, portanto, ele se caracteriza como uma etapa do processo político de investigação e ação educativa, inclusive em sua dimensão participativa, não sendo uma atividade neutra, mas que exibe um contínuo propósito coletivo (VIANNA, 1986).

Durante o segundo período de 2017, a disciplina do Estágio Supervisionado realizou reuniões semanais com os discentes, em que as questões sobre ensino, pesquisa e formação de professores eram levantadas. Nesse sentido, foi falado sobre o ato de Educar pela Pesquisa, explicitando para os alunos que por meio da pesquisa podemos compreender algumas das relações que estão postas na sociedade e desta forma compreender o ambiente e suas relações com o homem. Desta maneira, ao longo do processo os alunos foram compreendendo a relevância da pesquisa para a formação dos mesmos como futuros educadores.

Sendo assim, algumas propostas da disciplina eram que os alunos fizessem observação e prática em sala de aula e também realizassem um trabalho de pesquisa coletiva para compreender as relações de duas escolas da cidade com suas comunidades do entorno.

A fim de possibilitar aos estagiários uma reflexão acerca do trabalho que fariam, a professora coordenadora dos estágios propôs uma saída a campo, realizando uma dinâmica com os mesmos, em duplas, trabalhando alguns sentidos do corpo humano, assim como a percepção da ação do outro, do falar e do confiar, pois ao fazer uma pesquisa em educação, além da observação, é necessário se ater a outros fatores, para sermos capazes de interpretá-los.

A partir dessa dinâmica também foi possível discutir o ambiente a qual a instituição está inserida, observar seu entorno, sua comunidade e questionar quais as relações que ali existem. A partir destas reflexões, decidimos em quais escolas seria realizada a pesquisa e como ela se daria, ou seja, foi discutido o que seria importante observar no entorno para que isso refletisse no processo. Por intermédio de alguns fatores relatados pelos discentes, observados em sua vivência na escola, decidiu-se realizar esta pesquisa em duas escolas Estaduais da cidade de Lavras - MG, que serão aqui chamadas de escola $C$ (central) e escola $P$ (periférica), a fim de preservar suas identidades.

Como instrumento de coleta de dados utilizou-se a Entrevista não-dirigida. Segundo TozoniReis (2007) a entrevista tem como objetivo buscar informações por meio da "fala" dos sujeitos a serem ouvidos, os entrevistados. As entrevistas não-dirigidas são procedimentos de coleta de dados que se baseiam na forma de colher informações no discurso livre do entrevistado, pois permitem ao entrevistador reformular imediatamente o roteiro de entrevista, dependendo dos pontos abordados (CHIZZOTTI, 1998). 
Com o objetivo de coletar informações sobre a relação da escola com a comunidade foram construídas, coletivamente, questões que permitissem alcançar esse objetivo. Cada integrante da turma propôs uma questão que considerou importante, e a discussão sobre essas questões foram realizadas durante as reuniões semanais do estágio. As questões que compõem a entrevista utilizada nessa pesquisa foram pensadas tanto para integrantes da comunidade escolar, sendo eles professores, alunos e funcionários, quanto da comunidade do entorno. Após esse processo de construção do roteiro de questões, a turma dividiu-se em dois grupos e cada grupo ficou responsável por coletar dados em uma das escolas e na comunidade do entorno.

$\mathrm{Na}$ Escola Estadual C, realizou-se a coleta de dados em dois dias, um primeiro dia dentro da escola e no segundo dia fora da escola (com a comunidade). Na Escola Estadual P, as coletas de dados foram realizadas em três dias (dois dias com a comunidade, um dia com os integrantes da escola). Isso ocorreu com um certo atraso no cronograma, pelo fato de as escolas Estaduais de Lavras (e algumas outras da região) terem sido interditadas por uma ordem judicial que exigia reformas de medidas de segurança nas escolas.

Dentro do processo dessa pesquisa surgiram alguns obstáculos, como a universidade estar em um semestre pós-greve e o calendário letivo não estar sincronizado com o calendário das escolas, portanto, o tempo para realização da pesquisa foi reduzido.

Desta forma, no início da construção desta pesquisa, muitas questões foram levantadas, houve a criação de um banco de questões e logo após, uma seleção das perguntas que seriam mais relevantes para compreensão deste contexto.

Vale ressaltar que os dados coletados não se caracterizam como fiscalização do trabalho escolar, mas como diagnóstico das dificuldades encontradas nesse processo de relação com a comunidade pelos professores e pelos moradores, para que os alunos da disciplina pudessem refletir sobre o trabalho docente e o ato de educar.

Sendo assim, conhecendo estas limitações, os estudantes são capazes de criar formas de enfrentá-las no futuro como docentes, além de conhecerem o ambiente que envolve a escola e tudo que se relaciona a ela.

\section{RESULTADOS E DISCUSSÃO}

Para compreender a percepção dos professores sobre a possibilidade de se ensinar no bairro foram feitas duas perguntas durante as entrevistas nas escolas $C$ e $P$ : 
1. É possível utilizar o bairro como espaço de aprendizagem?

2. É possível relacionar o conteúdo da matéria com o entorno da escola?

\begin{tabular}{|c|c|l|}
\hline Escola & Total de professores entrevistados & \multicolumn{1}{|c|}{ Obs. } \\
\hline $\begin{array}{c}\text { Periférica (P) e } \\
\text { Central (C) }\end{array}$ & 9 & $\begin{array}{l}\text { Professores de química, física, } \\
\text { matemática, sociologia, biologia, } \\
\text { educação física, geografia e } \\
\text { português. }\end{array}$ \\
\hline
\end{tabular}

Para ambas as perguntas a maioria dos professores da escola $\mathrm{P}$ reconheceram que é possível utilizar outros espaços para o ensino e aprendizagem, assim como relacionar os conteúdos com o entorno, pois segundo eles, as matérias podem ser relacionadas com o cotidiano, com problemas ambientais e sociais do bairro, mas apesar disso, poucos já trabalharam desta forma com os alunos. Uma das professoras que leciona química e física disse já ter realizado atividades no entorno, levando os alunos para o espaço da Universidade, na represa do FUNIL e em uma nascente próxima. Uma minoria relatou que não faz essa saída porque não há tempo, no caso de disciplinas como sociologia e filosofia que só tem uma aula por semana. Além disso, a escola também exige que sejam aplicadas provas, portanto, não sobra tempo para essas atividades.

Já na escola C, alguns professores citaram que a localização da escola atrapalha, especialmente quando ela está em uma região central e comercial, muito movimentada. Apesar dos obstáculos apontados pelos professores, há possibilidades de se trabalhar a relação ambiente escola em espaços tão modificados e transformados como os centros das cidades. Consideramos que é importante que a questão ambiental não seja dissociada das questões sociais, assim, em uma escola localizada em uma região com comércio, poderiam ser discutidas questões como as funções sociais no trabalho, por exemplo quais serviços são mais realizados por negros e quais são mais realizados por brancos.

Ademais, é possível discutir com os alunos como era aquele ambiente antes da escola ser construída, como era a relação das pessoas que ali moravam com aquele ambiente, se havia presença ou ausência de vegetação, qual as características da biodiversidade local, quais animais estavam presentes e se haviam rios.

Algumas razões que podem estar relacionados com o fato de os professores, na maioria das vezes, não utilizarem o bairro pode estar pautada na pressão por terem que cumprir prazos estabelecidos no currículo, leis, regulamentos e questões burocráticas que impedem que os professores exerçam suas funções com autonomia, como fica claro nas falas dos professores que possuem poucas aulas durante a semana. Outro fator importante a se considerar é a própria formação de professores, quais deles tiveram oportunidades de refletir sobre a importância de ações educativas como estas? Ou aprendido como utilizar melhor esses espaços e como lidarem com os alunos fora da sala de aula (VILLAS-BOAS, 2009). Além disso, 
sair do ambiente escolar exige uma relação de confiança entre professor e alunos, o que é algo que leva tempo para ser construído.

Isso também acontece, porque muitas escolas brasileiras ainda trabalham segundo o método de ensino bancário (FREIRE, 1987). Nesse método de ensino, colocado também por Glória (2006) como ensino formal, a construção dos conhecimentos não é realizada em conjunto e não há um saber crítico voltado para a realidade dos alunos, por isso, muitos jovens vão à escola, mas não conseguem encontrar sentido no que estão estudando e acabam perdendo o interesse. Uma das maneiras de despertar o interesse dos estudantes para o que está sendo ensinado é utilizar de questões reais, tudo o que faz parte do seu cotidiano, incluindo a realidade do bairro na qual a escola está inserida (GLÓRIA, 2006).

Em todo momento de nossas vidas aprendemos algo, seja em nossa família, com amigos, vizinhos, no trabalho ou na escola, portanto, a educação ocorre continuamente e em todos os espaços (GLÓRIA, 2006). Ao utilizar o bairro como espaço de aprendizagem, surge a oportunidade de os alunos reconhecerem o lugar em que vivem, os moradores, quais as suas histórias e experiências e quais as culturas presentes no entorno (GLÓRIA, 2006). O contato com a diversidade de culturas possibilita aos jovens construírem sua identidade pessoal e reconhecer que o diferente também merece respeito. No bairro, o professor tem a oportunidade de problematizar a desigualdade presente, discutir questões que preocupam a comunidade e que interessam aos alunos, e abrir espaço para que eles proponham soluções, desenvolvendo-se assim a cidadania e gerando aprendizagens que não seriam realizadas no espaço escolar, o que segundo Glória (2006) contribui para que os alunos se voltem à resolução de problemas coletivos do cotidiano. Ao discutir problemas reais, os estudantes dão mais sentido para o que estão aprendendo, e ao utilizar outros espaços nos estudos, desenvolve-se a noção de que a aprendizagem se dá de várias formas e em diferentes espaços, não estando restrita à sala de aula.

Para compreender se há espaço para a participação da comunidade na escola, foram feitas algumas perguntas para os moradores dos bairros adjacentes às escolas.

1. Há oportunidade de participação na escola? Como?

2. Se houvesse a oportunidade de participar, você participaria?

\begin{tabular}{|c|c|l|}
\hline Escola & Total de pessoas entrevistadas & \multicolumn{1}{|c|}{ Obs. } \\
\hline Periférica $(\mathrm{P})$ & 30 & $\begin{array}{l}\text { Moradores do bairro da } \\
\text { escola e de bairros } \\
\text { adjacentes }\end{array}$ \\
\hline Central (C) & 17 & Residentes e comerciantes. \\
\hline
\end{tabular}

Para a primeira pergunta "Há oportunidade de participação na escola? Como?" dezessete, 17, pessoas entrevistadas no entorno da escola $C$ responderam; sendo que poucas pessoas 
responderam que sim, mostrando que há oportunidade de participar das festas juninas da escola, de encontros que envolvem contos de histórias e leituras, e a maior parte considera como participação reuniões para entrega de boletim escolar. Por outro lado, a maioria das pessoas do entorno da escola $C$ relataram que não há oportunidade de participação, que em outros momentos durante a sua vida já participaram, mas atualmente esse contato é escasso, seja por não terem mais filhos estudando lá ou pela escola não fazer esse contato com a comunidade.

Já para a segunda pergunta, "Se houvesse a oportunidade de participar, você participaria?" a maioria das pessoas que moram no entorno da Escola $\mathrm{C}$ disseram que sim, e uma minoria disse que não, e uma pessoa disse que já participou, mas não participaria novamente.

Aquelas que disseram que sim, sugeriram eventos como peças de teatro e eventos culturais, além de danças e criação de horta comunitária. Alguns comerciantes sugeriram que poderiam melhorar a sua relação com a escola fazendo parcerias com o fornecimento de alimentos, como foi o caso de uma padaria e uma loja de queijos, oferecendo descontos para os alunos. Foi dito também que uma forma de contribuir com a escola seria alertar sobre o uso de drogas, que pode ser visto por alguns comerciantes entrevistados durante o dia, sendo considerada por eles uma atividade rotineira.

Aqueles que disseram que mesmo se houvesse oportunidade de participação não participariam, justificaram a recusa pela falta de tempo, ou mesmo de interesse em se envolver com a escola. A única pessoa que já participou, mas não participaria mais, justificou dizendo que sua participação na escola se deu por conta de seus filhos que estudaram na escola e que agora por conta de sua idade, não tem mais interesse em participar.

Na escola P, para a primeira pergunta "Há oportunidade de participação na escola? Como?", grande parte disse que não há oportunidades de participação além da reunião de pais na escola ou se há, desconhecem. Para a segunda pergunta, "Se houvesse a oportunidade de participar, você participaria?", a maioria se interessou em participar de possíveis projetos na escola, sendo que foram colocadas várias propostas de projetos que a escola poderia oferecer à comunidade, como práticas agrícolas, horta comunitária, projetos de segurança e combate a drogas e esportes como futsal e ginástica. Estas ações podem contribuir para o melhor desempenho da escola e também como resolução de alguns problemas, como as drogas, por exemplo, observados em ambas as escolas.

A escola já possuiu uma horta comunitária, mas encontra dificuldades para dar continuidade ao projeto. Aqueles que disseram que não participariam, indicaram um problema relativo à segurança, especialmente devido ao histórico de tráfico de drogas que a mesma enfrenta, ou por falta de tempo devido às rotinas de trabalho.

Alguns dos entrevistados que moravam no entorno da escola periférica eram comerciantes, e estes relataram se sentirem desconfortáveis com alguns alunos porque quando eles saíam da escola frequentavam seus estabelecimentos e com um comportamento inadequado acabavam ameaçando as pessoas que não vendiam bebidas alcoólicas a eles, já que são menores de idade, e isso os deixava acuados. Essa é uma das atitudes que podem não favorecer uma integração entre a comunidade e a escola. 
A partir destas entrevistas, é possível notar como é importante a relação da escola com a comunidade para a construção do aluno como cidadão (VILLAS-BOAS, 2009). As características observadas durante as pesquisas puderam evidenciar isto devido às comunidades do entorno das escolas se mostrarem motivadas a participarem de possíveis projetos. Sendo assim, observando a escola e todas suas esferas, podemos romper com a visão de que a escola está restrita apenas à sua unidade física, além disso, ao realizar eventos esporádicos com a comunidade, a escola pode se aproximar da mesma e essa relação pode auxiliar tanto a escola em seu próprio trabalho quanto a aprendizagem dos alunos.

Nesse sentido, quando refletimos quais seriam os limites da esfera escolar, podemos pensar que os mesmos se restringem aos muros da escola, mas a mesma vai além de seus limites físicos, pois ela reflete a comunidade ao seu redor, e ambas necessitam de relação mútua para a formação cidadã dos indivíduos ali situados. Com isso, essa perspectiva vai de encontro ao que Glória (2006) chama de educação não-formal, em que os espaços educativos acompanham a trajetória de vida dos indivíduos em que há processos interativos intencionais. Segundo Sousa e Sarmento (2010), durante anos, a escola constituiu-se como um espaço fechado e à margem da comunidade, uma vez que lhe competia apenas a função de instrução. Este comportamento afastou a escola da comunidade, gerando um ensino não contextualizado com o ambiente vivido pelos alunos, que acabam tendo que aprender diversos conteúdos que não condizem com a sua realidade e para agravar a situação, muitas vezes a formação dos educandos tem como referência o mercado de trabalho e não a cidadania (KUENZER, 1999). Deste modo, o professor não deve descartar o saber que vem do cotidiano, aquele passado por gerações, que pode conversar com o científico, indispensável ao currículo de uma escola que contribui para a formação cidadã, para atuação coerente no ambiente em que os sujeitos vivem.

Embora nem sempre seja simples integrar a comunidade ao trabalho desenvolvido na escola, a comunidade tem muito a contribuir nesse sentido, enriquecendo-a culturalmente e contribuindo para que os próprios alunos se sintam integrantes, parte daquela escola. Ao se trabalhar em grupo e com a comunidade, os alunos podem criar diferentes concepções de mundo, além de aprenderem a ler e interpretar a sociedade que os cerca de maneira crítica e reflexiva, podendo contribuir para a construção coletiva da identidade e cidadania do grupo (GLÓRIA, 2006).

Todavia, para elaborar uma proposta de participação da comunidade no ambiente escolar é importante compreender a realidade social desta comunidade, ou seja, o contexto sócioespacial em que a escola está inserida e onde as famílias moram. É preciso considerar não apenas as famílias dos alunos, mas também outras pessoas que vivem na comunidade e que de alguma forma se relacionam com a escola (ALMEIDA, 2014).

Com isso, podemos dizer que a interação da escola com a comunidade é uma forma de melhorar a aprendizagem dos alunos e revelar que a comunidade pode participar do processo de construção dos valores da mesma. Porém, pesquisas afirmam que a escola e a comunidade se encontram distantes e que apesar de haver empenho de ambas as partes ainda existem obstáculos que impedem o envolvimento efetivo. 
Ao se abrir à comunidade, a escola deve possuir um espírito sensível e um olhar atento às realidades de vida, para poder contribuir na construção da cidadania e ser solidária, a partir do processo educativo, que com isso pode romper barreiras, como preconceito e diferenças, tornando possível a convivência humana de forma mais fraterna (REINHARDT, 2008). Mas esta é uma tarefa grandiosa, que exige muito esforço, dedicação e permanente ação-reflexão.

Em suma, para se tornar um cidadão crítico de fato, é preciso, inicialmente, conhecer o ambiente em que se vive, compreendendo todas as suas nuances políticas, culturais, sociais e ambientais, por exemplo. Isso é necessário porque a relação dos indivíduos com a natureza é mediada pelas relações sócio-culturais e das classes historicamente construídas (LAYRARGUES, 2012). Por conta disso, para viver em sociedade e entender o seu papel nela, as pessoas precisam se dar conta destas relações em seu meio, e ao compreendê-las, elas terão autonomia para refletir e exercer o seu trabalho.

Para passar por esse processo de compreensão da realidade, entende-se que a escola apresenta o melhor potencial. Afinal, por meio de uma educação libertária e emancipadora, os indivíduos tomam consciência de si, do trabalho e da relação homem-natureza (FREIRE, 1987). Da mesma forma, ao estabelecerem relação com a comunidade do entorno, podem suscitar a participação social das pessoas da instituição educativa e também aquelas da comunidade. Essa participação é muito importante para que as pessoas tenham seus direitos garantidos e possam ter liberdade de pensamento, compreensão da realidade e posicionamento crítico.

A partir das entrevistas podemos perceber que a participação da comunidade na escola ocorre muito pouco, da mesma forma os professores encontram dificuldades de trabalharem com seus alunos no bairro. Isso é uma dificuldade que pode ser percebida pela Educação Ambiental, pois nem sempre ela é trabalhada nesse aspecto, de conhecer o ambiente e suas relações com as pessoas, mas sim em um aspecto conservacionista.

Esse processo de conhecer o ambiente em que a escola está inserida pode levantar algumas questões a serem problematizadas pela educação ambiental, por exemplo, levantamento de fauna e flora do local, percebendo como era antes e como é hoje e como ocorreram essas transformações. Por meio desse ensino, os alunos também são capazes de compreender a relação das pessoas que ali vivem com a natureza, assim como iniciar um processo de investigação sobre problemas ambientais vivenciados pelos moradores do bairro onde a escola se situa.

Desta forma, investigar quais as relações da comunidade do entorno com as escolas em questão permite que os alunos tenham uma visão clara e ampla do que significa meio ambiente, e ao mesmo tempo se sentem pertencentes àquele ambiente.

\section{CONSIDERAÇÕES FINAIS}

O presente trabalho, realizado com as comunidades de duas escolas públicas de um município do Sul de Minas Gerais pode levantar muitas questões e suas "situações problema" (como tráfico de drogas) e os problemas que os professores enfrentam que os impedem de levar a aula para fora do espaço físico da escola. A partir disso é possível refletir sobre as possibilidades de trabalho coletivo dos diferentes agentes educacionais com a comunidade, 
considerando o seu ambiente real como conteúdo e espaço de aprendizagem. O estreitamento entre as relações escola comunidade pode fomentar mudanças no ambiente educacional, promovendo melhorias na relação entre funcionários, estudantes e comunidade no funcionamento escolar e para o processo de ensino-aprendizagem.

A pesquisa possibilitou um olhar mais crítico e atencioso para estas questões, o que pode promover futuros benefícios, estreitando as relações entre estas escolas e as Universidades, gerando parcerias com laboratórios, museu, esportes, cultura e lazer. A "ação" pode não ser imediata, mas primeiramente (e principalmente) contribuiu com o seu processo, no sentido da formação dos futuros professores, desenvolvendo seu espírito investigativo em busca de melhorias no processo de ensino-aprendizagem.

Além disso, a pesquisa se revela muito importante para a formação inicial de professores, pois a partir do processo de investigação os estudantes perceberam a importância de conhecer o ambiente que envolve a escola. Assim como refletiram sobre os possíveis espaços para problematização das questões que cercam o âmbito educacional.

A partir da investigação das dificuldades encontradas na relação entre escola e comunidade, os estudantes foram capazes de refletir o papel da educação ambiental de conhecer o ambiente e suas relações sociais, culturais e políticas de participação social. Assim, refletindo sobre esse papel, os mesmos constroem uma visão ampla e integral do meio ambiente, levando em consideração que a educação ambiental é também crítica, pois não focaliza suas preocupações somente na conservação do meio ambiente físico.

\section{AGRADECIMENTO}

CAPES, FAPEMIG e UFLA.

\section{REFERÊNCIAS}

ALMEIDA, Luana Costa; BETINI, Geraldo Antonio. Investigação sobre a escola e seu entorno: Estudo bibliográfico de produções nacionais. Revista de Educação Pública, v. 24, n. 55, p. 33-56, 2014.

CHIZZOTTI, Antonio. (1998). Pesquisa em Ciências Humanas e Sociais. São Paulo: Cortez.

DEMO, Pedro. Educar pela pesquisa. In: Educar pela pesquisa. 2011.

FESTOZO, Marina Battistetti et al. Relações Históricas entre a Educação Ambiental e a Participação Social. Revista Tempos e Espaços em Educação, v. 11, n. 24, p. 253-266, 2018.

FREIRE, Paulo. Pedagogia do oprimido. 17a. Ed. Rio de Janeiro: Paz e Terra, v. 3, 1987.

GLÓRIA, Maria Gohn. Educação não-formal, participação da sociedade civil e estruturas colegiadas nas escolas. Rio de Janeiro: Revista Ensaio-Avaliação e Políticas Públicas em Educação, v. 14, n. 50, p. 11-25, 2006.

KUENZER, Acacia Zeneida. As políticas de formação: a constituição da identidade do professor sobrante. Educação e sociedade, v. 20, n. 68, p. 163-183, 1999.

LAYRARGUES, Philippe Pomier. A dimensão freireana na Educação Ambiental. Educação Ambiental: dialogando com Paulo Freire. São Paulo: Cortez, p. 7-12, 2012. 
LÜDKE, Menga; ANDRÉ, Marli EDA. Métodos de coleta de dados: observação, entrevista e análise documental. Pesquisa em educação: abordagens qualitativas. São Paulo (SP): EPU, 1986.

MEKSENAS, Paulo. Pesquisa social e ação pedagógica. Edições Loyola, 2002.

REINHARDT, Rosemari Dorigon. Parceria entre a Escola e a Comunidade na Perspetiva da Gestão Solidária. Boletim da saúde, 2007.

SAVIANI, Dermeval. Escola e democracia: teorias da educação, curvatura da vara, onze teses sobre a educação política. 33. ed. Campinas: Autores Associados, 2000.

SAVIANI, Dermeval. Sobre a natureza e especificidade da educação. Pedagogia Histórico-Crítico: primeiras aproximações. São Paulo: Cortez, Autores Associados, 3 ed., p. 19-30, 1992.

SEVERINO, Antônio Joaquim. Educação e universidade: conhecimento e construção da cidadania. InterfaceComunicação, Saúde, Educação, v. 6, p. 117-124, 2002.

SLEUTJES, Maria Helena Silva Costa. Refletindo sobre os três pilares de sustentação das universidades: ensinopesquisa-extensão. Revista de Administração Pública, v. 33, n. 3, p. 99-101, 1999.

SOUSA, Maria Martins de; SARMENTO, Teresa. Escola-família-comunidade: uma relação para o sucesso educativo. Gestão e Desenvolvimento, v. 17, p. 141-156, 2010.

TOZONI-REIS, Marília Freitas C. Metodologia de Pesquisa. IESDE BRASIL SA, 2008.

TOZONI-REIS, Marília Freitas de Campos. Pesquisa-ação em educação ambiental. Pesquisa em educação ambiental, v. 3, n. 1, p. 155-169, 2012.

VIANNA, Ilca Oliveira de Almeida. Planejamento participativo na escola. Um desafio ao educador. São Paulo: Editora pedagógica e universitária, 1986.

VILLAS-BOAS, Maria Adelina. A relação escola-família-comunidade inserida na problemática da formação de professores. Universidade de Lisboa (FPCE), 2009. 